\title{
Severe obesity prior to diagnosis limits survival in colorectal cancer patients evaluated at a large cancer centre
}

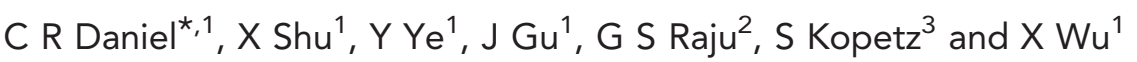 \\ ${ }^{1}$ Department of Epidemiology, Division of OVP, Cancer Prevention and Population Sciences, The University of Texas MD \\ Anderson Cancer Center, Unit 1340, 1515 Holcombe Boulevard, Houston, TX 77030, USA; ${ }^{2}$ Department of Gastroenterology, \\ Hepatology, and Nutrition, Division of Internal Medicine, The University of Texas MD Anderson Cancer Center, Houston, TX, USA \\ and ${ }^{3}$ Department of Gastrointestinal Medical Oncology, Division of Cancer Medicine, The University of Texas MD Anderson \\ Cancer Center, Houston, TX, USA
}

Background: In contrast to the consistent evidence for obesity and colorectal cancer (CRC) risk, the impact of obesity in CRC patients is less clear. In a well-characterised cohort of CRC patients, we prospectively evaluated class I and class II obesity with survival outcomes.

Methods: The CRC patients $(N=634)$ were followed from the date of diagnosis until disease progression/first recurrence (progression-free survival (PFS)) or death (overall survival (OS)). Body mass index (BMI) was calculated from reported usual weight prior to diagnosis. Hazard ratios (HRs) and $95 \%$ confidence intervals (Cls) were estimated in models adjusted for clinicopathologic, treatment, and lifestyle factors.

Results: Over a median follow-up of 4 years, 208 (33\%) patients died and 235 (37\%) recurred or progressed. Class II obesity, as compared with either overweight or normal weight, was associated with an increased risk of death (HR and $95 \% \mathrm{Cl}: 1.55$ (0.97-2.48) and 1.65 (1.02-2.68), respectively), but no clear association was observed with PFS. In analyses restricted to patients who presented as stages I-III, who reported stable weight, or who were aged $<50$ years, obesity was associated with a significant two- to five-fold increased risk of death.

Conclusions: In CRC patients evaluated at a large cancer centre, severely obese patients experienced worse survival outcomes independent of many other factors.

Colorectal cancer (CRC) remains the second leading cause of cancer mortality among US men and women combined, with an estimated 132700 new cases and 49700 deaths expected in 2015 (American Cancer Society, 2015). Refinements in screening and treatment strategies have improved survival of this disease; and currently, over 1 million CRC survivors are living in the United States (American Cancer Society, 2015).

Obesity is an established risk factor involved in the development of CRC via inflammation, metabolism, hormone and cytokine signalling that may continue to play a significant role in disease recurrence and survival outcomes among CRC patients after treatment (Demark-Wahnefried et al, 2012; Bardou et al, 2013; Gibson et al, 2014). Despite concentrated public health efforts, no significant changes or improvements in overall US obesity rates have been observed over the past 10 years, whereas the rates of morbid obesity continue to increase (Flegal et al, 2012; Sturm and Hattori, 2013). Currently, more than one-third of all adults, as well as CRC survivors, living in the United States are obese (body mass index (BMI) $\geqslant 30 \mathrm{~kg} \mathrm{~m}^{-2}$ ) (Flegal et al, 2012; Sturm and Hattori, 2013). Approximately $15 \%$ of middle-aged adults (age $40-59$ years;

*Correspondence: Dr CR Daniel; E-mail: cdaniel@mdanderson.org

Received 7 August 2015; revised 4 November 2015; accepted 12 November 2015; published online 17 December 2015

(c) 2016 Cancer Research UK. All rights reserved 0007-0920/16 
Ogden et al, 2014) meet the criteria for class II obesity $\left(\mathrm{BMI} \geqslant 35 \mathrm{~kg} \mathrm{~m}^{-2}\right)$ including the age group $(50+$ years $)$ most commonly diagnosed and treated for colorectal and other cancers (American Cancer Society, 2015). This not only presents a significant problem for cancer prevention, but as we improve our treatment capabilities, it may also present challenges for long-term survival in obese cancer patients.

The American Cancer Society recommendations for cancer patients and survivors are similar to those for cancer prevention and state that in addition to not smoking, eating a healthy diet, and being physically active, individuals maintain a normal weight (Doyle et al, 2006). However, a U-shaped relationship with improved survival among overweight, as compared with normal and underweight, CRC patients has also been observed (Hines et al, 2009; Sinicrope et al, 2010; Baade et al, 2011; Min et al, 2012; Schlesinger et al, 2014; Wu et al, 2014), and suggests that moderate adiposity or overweight status may be protective for initially enduring the arduous cancer process (Parkin et al, 2014; Renehan, 2014; Schlesinger et al, 2014). With tumour stage, treatment, and cancer-associated weight loss linked to inconsistencies in prior analyses of BMI and CRC cancer patient survival (Simkens et al, 2011; Parekh et al, 2012; Bardou et al, 2013; Boyle et al, 2013; Sinicrope et al, 2013; Azvolinsky, 2014; Parkin et al, 2014), clarifying whether obesity is an independent prognostic factor and what is not a healthy weight for cancer patients remains both a clinically relevant and timely concern. In a cohort of well-characterised CRC patients, we prospectively evaluated the association of class I (BMI $30-34.9 \mathrm{~kg} \mathrm{~m}^{-2}$ ) and class II ( $\geqslant$ BMI $35 \mathrm{~kg} \mathrm{~m}^{-2}$ ) obesity with survival outcomes.

\section{MATERIALS AND METHODS}

Study cohort. As reported previously (Ye et al, 2012), 1103 histologically confirmed colorectal adenocarcinoma patients were recruited between January 1990 and June 2008 at the University of Texas MD Anderson Cancer Center (MDACC). Of these, 745 patients were newly diagnosed (within 1 year of referral to the cancer centre); and over $90 \%$ were diagnosed within 3 months of recruitment into the study. We collected epidemiological data through a self-administered questionnaire and abstracted treatment and clinicopathologic data from patients' electronic medical records. Of these, 634 patients had complete data, including BMI, for the current analysis. The study was approved by the Institutional Review Board of MD Anderson Cancer Center and informed consent was obtained from each study participant.

Study variables. We examined the following survival end points: progression/recurrence-free survival (PFS) defined as the time from pathologic diagnosis until disease progression or first recurrence; and overall survival (OS) defined as the time from pathologic diagnosis until the date death from any cause, as captured by the MDACC tumour registry (Eng and Skibber, 2013). In patients without a reported death date, follow-up was defined as the date of last contact. BMI $\left(\mathrm{kg} \mathrm{m}^{-2}\right)$ was calculated from the patient's height and self-reported usual weight prior to diagnosis and categorised as normal (BMI $<25 \mathrm{~kg} \mathrm{~m}^{-2}$ ), overweight (BMI 25 to $<30 \mathrm{~kg} \mathrm{~m}^{-2}$ ), class I obesity (BMI 30 to $<35 \mathrm{~kg} \mathrm{~m}^{-2}$ ), and class II obesity (BMI $\geqslant 35 \mathrm{~kg} \mathrm{~m}^{-2}$ ) according to WHO guidelines (Word Health Organization, 2000). Peridiagnostic weight change (prior to the initiation of treatment) was further informed by electronic medical record data and defined as weight loss, weight stable, weight gain, or unknown. We derived an 8-level categorical treatment variable based on common combinations used in clinical practice: (1) surgery only; (2) Fluorouracil (5-FU) chemotherapy with molecular target therapy (MTT) and/or 5-FU with radiation; (3) Capecitabine (CAPE) or other chemotherapy with MTT and/or CAPE or other chemotherapy with radiation; (4) surgery and 5-FU with MTT; (5) surgery and CAPE or other chemotherapy with MTT; (6) surgery and CAPE with radiation; (7) surgery and other chemotherapy with radiation; and (8) unknown treatment $(<2 \%)$. Inclusion $v s$ exclusion of the missing categories for clinicopathologic variables of interest (all $\leqslant 2 \%$ ) did not meaningfully change the estimates observed.

Statistical analysis. To assess the association of demographic and clinical variables with survival, we used the $\chi^{2}$ and nonparametric log-rank test, as appropriate. We evaluated the association of prediagnostic BMI in relation to prospective survival outcomes using Cox proportional hazards regression models adjusted for age, sex, alcohol drinking status, clinical stage, grade, treatment modality, and weight change (defined in Table 1). Additional adjustment for history of diabetes, smoking status, and other covariates did not meaningfully alter estimates presented. Hazard ratios (HRs), 95\% confidence intervals (CIs), and $P$-values for trend (using the median value within each category) are reported across BMI categories. The proportional hazards assumption was satisfied by evaluating the cross-product of BMI and time $(P=0.73)$. Survival curves were generated using the KaplanMeier method and statistical significance was measured using the log-rank test. We also assessed whether associations with BMI varied by $\mathrm{CRC}$ risk and prognostic factors mentioned in previous reports (American Cancer Society, 2014; Parkin et al, 2014; Renehan, 2014; Wu et al, 2014), including age, sex, smoking status, history of diabetes, weight change, and tumour stage. Statistical tests for interaction evaluated the significance of categorical crossproduct terms in the multivariable adjusted models. All statistical analyses were performed using STATA version 10.0 (Stata Co., College Station, TX, USA). $P$-values are two sided and considered statistically significant at $P<0.05$.

\section{RESULTS}

Characteristics of the 634 colon and rectal cancer patients are presented in Table 1. Over a median follow-up of 4 years post diagnosis, 208 (33\%) patients died and 235 (37\%) recurred or progressed. Majority of the CRC patients were over 50 years of age, white, male, and overweight or obese; approximately half reported never smoking or consuming alcohol. Among those with known disease stage (98\%), two-thirds had localised or locally advanced disease. Obese patients (BMI $\geqslant 30 \mathrm{~kg} \mathrm{~m}^{-2}$ ), as compared with nonobese patients (BMI $<30 \mathrm{~kg} \mathrm{~m}^{-2}$ ), were more likely to be male and to report a positive history of type II diabetes mellitus (data in Supplementary Table S1). Weight loss prior to diagnosis was reported in $37 \%$ of lean patients (BMI $<25 \mathrm{~kg} \mathrm{~m}^{-2}$ ) as compared with $27 \%, 26 \%$, and $10 \%$ of overweight (BMI 25 to $<30 \mathrm{~kg} \mathrm{~m}^{-2}$ ), class I (BMI 30 to $<35 \mathrm{~kg} \mathrm{~m}^{-2}$ ), and class II $\left(\right.$ BMI $>35 \mathrm{~kg} \mathrm{~m}^{-2}$ ) obese patients, respectively (Supplementary Table S1). No other significant differences across BMI categories were observed for age at diagnosis, tumour characteristics, or treatment modality. Patients who reported recent weight loss, as compared with patients who reported stable weight, were more likely to be current smokers (pair-wise $P=0.08$ ) and to have advanced tumours $(P<0.001$; data not shown).

The associations of demographic, clinical, and treatment characteristics with 10-year OS among CRC patients are shown in Table 2. Survival significantly differed by tumour characteristics (stage and grade), treatment modality, and weight change. Similar associations were observed for stage and treatment modality with PFS; however, no differences were observed by BMI or weight change (data in Supplementary Table S2).

The univariate analysis revealed a U-shaped relationship between BMI and survival, with the highest risk of death observed 
Table 1. Selected demographic, lifestyle, and clinical characteristics of colorectal cancer patients, $N=634^{a}$

\begin{tabular}{|c|c|}
\hline Characteristic & Count $(\%)^{b}$ \\
\hline Age-mean (s.d.), years & $56.8(13.1)$ \\
\hline Male & $391(61.7)$ \\
\hline White & 515 (81.2) \\
\hline African American & $49(7.7)$ \\
\hline Other race & $69(10.9)$ \\
\hline Unknown & $1(0.2)$ \\
\hline History of type II diabetes & $80(12.6)$ \\
\hline Never smoker & $341(53.8)$ \\
\hline Former smoker & $228(36.0)$ \\
\hline Current smoker & $59(9.3)$ \\
\hline Unknown & $29(4.6)$ \\
\hline Pack-years, median (10-90\%) & $20(5-62)$ \\
\hline Never drinker & $302(47.6)$ \\
\hline Former drinker & $106(16.7)$ \\
\hline Current drinker & $212(33.4)$ \\
\hline BMI mean (s.d.), $\mathrm{kg} \mathrm{m}^{-2}$ & $28.5(5.8)$ \\
\hline BMI $<25$ & $173(27.3)$ \\
\hline BMI 25-29.9 & 237 (37.4) \\
\hline BMI 30-34.9 & $150(23.7)$ \\
\hline $\mathrm{BMI} \geqslant 35$ & $74(11.7)$ \\
\hline Reported weight loss & $147(23.2)$ \\
\hline Weight stable & $379(59.8)$ \\
\hline Weight change not specified & $108(17.0)$ \\
\hline \multicolumn{2}{|l|}{ Tumour characteristics } \\
\hline Stage I & $59(9.3)$ \\
\hline Stage II & 149 (23.5) \\
\hline Stage III & 201 (31.7) \\
\hline Stage IV & $213(33.6)$ \\
\hline Unknown & $12(1.9)$ \\
\hline Grade $^{c} 1$ & $27(4.3)$ \\
\hline Grade 2 & $500(78.9)$ \\
\hline Grade 3 & $93(14.7)$ \\
\hline Unknown & $14(2.2)$ \\
\hline Proximal colon & $144(22.7)$ \\
\hline Distal colon & $147(23.2)$ \\
\hline Rectum & 339 (53.5) \\
\hline \multicolumn{2}{|l|}{ Treatment characteristics } \\
\hline Primary tumour curative surgery & $542(85.5)$ \\
\hline Surgery only & $116(18.3)$ \\
\hline Chemo and MTT & 438 (69.1) \\
\hline 5-FU & $295(67.3)$ \\
\hline CAPE & $128(29.2)$ \\
\hline Other & $14(3.2)$ \\
\hline Chemo and radiation & $268(42.3)$ \\
\hline CAPE & $225(84.0)$ \\
\hline Other & $43(16.0)$ \\
\hline
\end{tabular}

Abbreviations: $\mathrm{BMI}=$ body mass index; $\mathrm{CAPE}=$ capecitabine; 5 -FU = 5-fluorouracil; $\mathrm{MTT}=$ molecular target therapy.

${ }^{a}$ All incident patients were recruited within 1 year (90\% within 3 months) of diagnosis.

${ }^{b_{N}}(\%)$ unless otherwise specified; does not add up to $100 \%$ because of $<2 \%$ missing for some variables.

${ }^{\mathbf{c}}$ Grades: 1: well differentiated; 2: moderately differentiated; 3: poorly differentiated.

among the lowest (BMI $<25 \mathrm{~kg} \mathrm{~m}^{-2}$ ) and highest (BMI $\geqslant 35 \mathrm{~kg} \mathrm{~m}^{-2}$ ) categories (Table 3 and Figure 1). The lowest risk of death was observed among the overweight patients (BMI 25$29.9 \mathrm{~kg} \mathrm{~m}^{-2}$ ), which was set as the referent category. However, following adjustment for age, sex, alcohol status, weight change, tumour, and treatment characteristics, this relationship was attenuated for the BMI $<25 \mathrm{~kg} \mathrm{~m}^{-2}$ category. In the multivariable model with overweight as the referent category, we observed a nearly significant direct association between class II obesity and
Table 2. Association between colorectal cancer patient characteristics and 10-year mortality, $N=634$

\begin{tabular}{|c|c|c|c|}
\hline Variables & Alive & Dead & Log-rank $P$ \\
\hline Age $<50$ & $114(66.7)$ & 57 (33.3) & \\
\hline Age $\geqslant 50$ & $312(67.4)$ & $151(32.6)$ & 0.652 \\
\hline Male & $258(66.0)$ & $133(34.0)$ & \\
\hline Female & $168(69.1)$ & $75(30.9)$ & 0.148 \\
\hline White & $349(67.8)$ & $166(32)$ & \\
\hline African American & $31(63.3)$ & $18(36.7)$ & \\
\hline Other race & $46(66.7)$ & $23(33.3)$ & 0.692 \\
\hline Never drinker & $193(63.9)$ & $109(36)$ & \\
\hline Former drinker & $80(75.5)$ & $26(24.5)$ & \\
\hline Current drinker & $146(68.9)$ & $66(31.1)$ & 0.060 \\
\hline Never smoker & $233(68.3)$ & $108(32)$ & \\
\hline Former smoker & $151(66.2)$ & $77(33.8)$ & \\
\hline Current smoker & $38(64.4)$ & $21(35.6)$ & 0.576 \\
\hline Pack-years $=0$ (never smokers) & $233(68.3)$ & $108(32)$ & \\
\hline Pack-years $<30$ & $108(62.1)$ & $66(37.9)$ & \\
\hline Pack-years $\geqslant 30$ & $63(70.0)$ & $27(30.0)$ & 0.434 \\
\hline No type II diabetes & $375(67.7)$ & $179(32.3)$ & \\
\hline Yes type II diabetes & $51(63.8)$ & $29(36.3)$ & 0.589 \\
\hline $\mathrm{BMI}<25 \mathrm{~kg} \mathrm{~m}^{-2}$ & $106(61.3)$ & $67(38.7)$ & \\
\hline BMI $25-29.9 \mathrm{~kg} \mathrm{~m}^{-2}$ & $175(73.8)$ & $62(26.2)$ & \\
\hline BMI $30-35 \mathrm{~kg} \mathrm{~m}^{-2}$ & $100(66.7)$ & $50(33.3)$ & \\
\hline $\mathrm{BMI} \geqslant 35 \mathrm{~kg} \mathrm{~m}^{-2}$ & $45(60.8)$ & $29(39.2)$ & 0.051 \\
\hline Weight loss & 77 (52.4) & $70(48)$ & \\
\hline Weight stable & $273(72.0)$ & $106(28.0)$ & \\
\hline Weight change not specified & $76(70.4)$ & $32(29.6)$ & $<0.001$ \\
\hline \multicolumn{4}{|l|}{ Tumour characteristics } \\
\hline Proximal colon & $98(68.1)$ & $46(32)$ & \\
\hline Distal colon & $91(61.9)$ & $56(38.1)$ & \\
\hline Rectum & $236(69.6)$ & $103(30.4)$ & 0.116 \\
\hline Stage 1 & $53(89.8)$ & $6(10.2)$ & \\
\hline Stage II & 112 (75.2) & 37 (24.8) & \\
\hline Stage III & $172(85.6)$ & 29 (14.4) & \\
\hline Stage IV & $79(37.1)$ & $134(62.9)$ & $<0.001$ \\
\hline Grade $^{a_{1}}$ & $22(81.5)$ & 5 (19) & \\
\hline Grade 2 & 351 (70.2) & $149(29.8)$ & \\
\hline Grade 3 & $47(50.5)$ & $46(49.5)$ & $<0.001$ \\
\hline \multicolumn{4}{|l|}{ Treatment characteristics } \\
\hline Surgery only & $90(77.6)$ & $26(22.4)$ & \\
\hline $\begin{array}{l}\text { No surgery, } 5 \text {-FU with MTT and/or } \\
\text { with radiation }\end{array}$ & $12(21.8)$ & $43(78.2)$ & \\
\hline $\begin{array}{l}\text { No surgery, CAPE/other chemo } \\
\text { with MTT and/or with radiation }\end{array}$ & $6(25.0)$ & $18(75.0)$ & \\
\hline Surgery and 5-FU with MTT & $83(60.1)$ & $55(39.9)$ & \\
\hline $\begin{array}{l}\text { Surgery and CAPE/other chemo } \\
\text { with MTT }\end{array}$ & $39(166.0)$ & $11(110.0)$ & \\
\hline Surgery and CAPE with radiation & $163(41.9)$ & $35(27.8)$ & \\
\hline $\begin{array}{l}\text { Surgery and other chemo with } \\
\text { radiation }\end{array}$ & $29(207.5)$ & $11(137.5)$ & $<0.001$ \\
\hline
\end{tabular}

10 -year OS (BMI $\geqslant 35$ vs BMI $25-29.9 \mathrm{~kg} \mathrm{~m}^{-2}$ (ref), HR: 1.55 ; 95\% CI: 0.97-2.48). Consistent associations were observed across BMI categories in multivariable models with lean patients $\left(\mathrm{BMI}<25 \mathrm{~kg} \mathrm{~m}^{-2}\right.$ ) as the referent category (HR and 95\% CI: 1.00 (ref); 0.99 (0.67-1.46); 1.11 (0.74-1.67); 1.65 (1.02-2.68), respectively; $P$-trend $=0.08$; data in text only).

In analyses restricted to patients with localised or locally advanced disease, both class I and class II obesity, as compared with overweight, were associated with significantly worse OS (Table 3), but null associations were observed in metastatic patients 
(Figure 2). Similarly, the finding for severe obesity was more pronounced among patients who reported stable weight (Table 3 ), whereas no association was observed among the group that reported weight loss $(P$-trend $=0.91)$ or that did not specify $(P$-trend $=0.87$; data not shown $)$. Class II obesity also remained significantly associated with OS in analyses restricted to patients who were never smokers (HR: $2.09,95 \% \mathrm{CI}$ : $1.07-4.08, P=0.03$; Figure 2), patients without a history of type II diabetes (HR: 1.98, 95\% CI: 1.17-3.37, $P=0.01$; data in text only), and patients diagnosed prior to age 50 years (HR: 4.94, 95\% CI: 1.66-14.70, $P=0.004$; Figure 2).

No statistically significant associations were observed across BMI categories and PFS in overall multivariable models (HR and 95\% CI: 0.89 (0.63-1.26), 1.00 (ref), 0.97 (0.67-1.40), 1.28 (0.82-1.99), $P=0.32$; data presented in Supplementary Table S3). However, in analyses restricted to never smokers, class II obesity was associated with an increased risk of progression/

Table 3. Association between prediagnostic BMI $\left(\mathrm{kg} \mathrm{m}^{-2}\right)$ and 10-year mortality in colorectal cancer patients

\begin{tabular}{|c|c|c|c|c|c|c|}
\hline & \multicolumn{3}{|c|}{ Univariate } & \multicolumn{3}{|c|}{ Multivariate $^{a}$} \\
\hline Variables & HR & $95 \% \mathrm{Cl}$ & $P_{\text {trend }}$ & $\mathrm{HR}$ & $95 \% \mathrm{Cl}$ & $P_{\text {trend }}$ \\
\hline \multicolumn{7}{|c|}{ All patients $(N=634)$} \\
\hline$<25$ & 1.60 & $1.13-2.26$ & & 1.04 & $0.71-1.52$ & \\
\hline & 1.00 & & & 1.00 & & \\
\hline & 1.22 & 0.84 & & 1.13 & $0.76-1$ & \\
\hline$\geqslant 35$ & 1.45 & $0.93-2.25$ & 0.54 & 1.55 & $0.97-2.48$ & 0.14 \\
\hline \multicolumn{7}{|c|}{ Stage I-III patients $(N=409)$} \\
\hline$<25$ & 1.70 & $0.85-3.41$ & & 1.59 & $0.74-3.43$ & \\
\hline $25-29.9$ & 1.00 & & & 1.00 & & \\
\hline $30-34.9$ & 2.06 & $1.08-3.92$ & & 2.21 & $1.11-4.40$ & \\
\hline$\geqslant 35$ & 3.38 & $1.72-6.64$ & 0.009 & 3.49 & $1.68-7.22$ & 0.007 \\
\hline \multicolumn{7}{|c|}{ Stable-weight patients $(N=379)$} \\
\hline$<25$ & 1.25 & $0.76-2.07$ & & 1.17 & $0.66-2.09$ & \\
\hline $25-29.9$ & 1.00 & & & 1.00 & & \\
\hline $30-34.9$ & 1.05 & $0.61-1.79$ & & 1.36 & $0.75-2.46$ & \\
\hline$\geqslant 35$ & 2.35 & $1.38-3.98$ & 0.07 & 2.60 & $1.42-4.76$ & 0.01 \\
\hline \multicolumn{7}{|c|}{$\begin{array}{l}\text { Abbreviations: } \mathrm{Cl}=\text { confidence interval; } \mathrm{BMI}=\text { body mass index; } \mathrm{HR}=\text { hazard ratio, } \\
\text { Ref=reference. } \\
{ }^{2} \text { Model adjusted for age, sex, alcohol drinking status, weight change, clinical stage, grade, } \\
\text { and treatment modality. }\end{array}$} \\
\hline
\end{tabular}
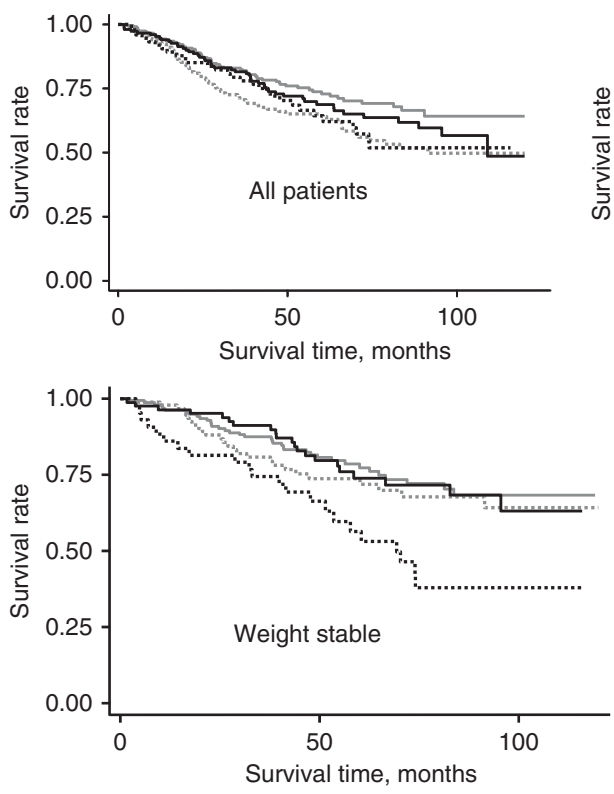

Figure 1. Kaplan-Meier 10-year survival curves. recurrence (BMI > 35 vs 25.0-29.9 $\mathrm{kg} \mathrm{m}^{-2}$ (ref), HR and 95\% CI: $1.85(1.03-3.30))$.

Restricting the analyses to the 585 patients recruited within 3 months of CRC diagnosis and exclusion of 8 underweight patients $\left(\mathrm{BMI}<18.5 \mathrm{~kg} \mathrm{~m}^{-2}\right)$ from the lowest BMI $<25 \mathrm{~kg} \mathrm{~m}^{-2}$ category did not materially change estimates presented. Although some of the subgroup findings were more pronounced, no statistically significant tests for interaction by strata were observed for BMI and OS or BMI and PFS (all P-interaction >0.07).

\section{DISCUSSION}

Although several other groups have explored the link between BMI and CRC patient outcomes, we aimed to address some of the unresolved analytic inconsistencies leading to the 'insufficient evidence for a strong link between adiposity and survival,' as noted in the review by Parkin et al (2014). With careful consideration of important risk and prognostic factors, the association between prediagnostic BMI and OS in all CRC patients was modest. Our most robust and consistent findings were for more extreme levels of obesity and among patient subgroups, as observed previously (Parkin et al, 2014; Renehan, 2014; Wu et al, 2014). Among patients with local or locally advanced disease and among patients diagnosed aged $<50$ years, both class I and class II obesity were associated with a two-fold to five-fold increased risk of death as compared with overweight patients. Similarly, among CRC patients who did not experience weight loss prior to diagnosis and treatment, severe obesity was associated with a more than twofold risk of death, but no clear association was observed among metastatic patients, older patients, or among patients who experienced prior weight loss. When adjusted for other important demographic and clinicopathologic factors, including treatment, we observed no excess risk among lean or overweight patients.

Severe or class II obesity has been previously linked to significantly worse survival outcomes as compared with all other BMI categories and independent of other prognostic factors in patients with colon (Murphy et al, 2000; Dignam et al, 2006; Sinicrope et al, 2010), pancreatic (Fleming et al, 2009; Yuan et al, 2013), and breast cancer (Pajares et al, 2013). Excess adipose tissue, as the body's largest active endocrine organ, may limit survival in cancer patients via energy balance and
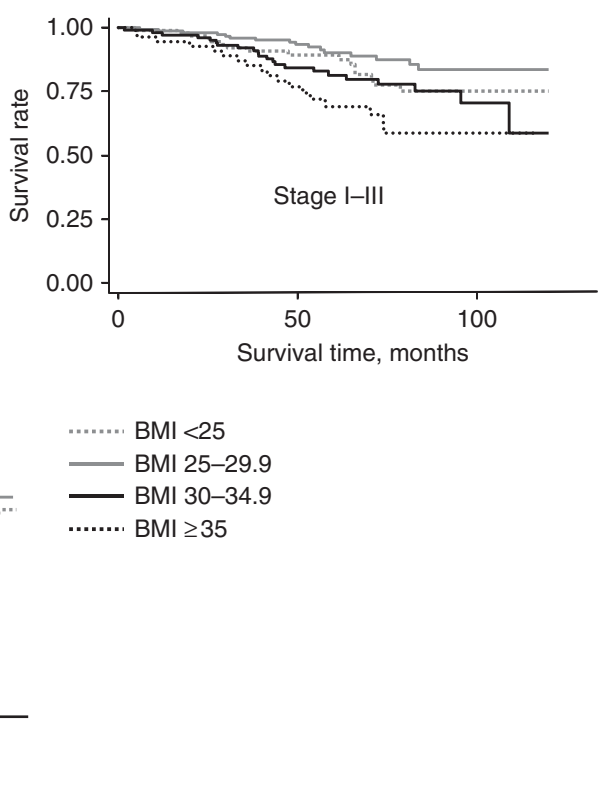

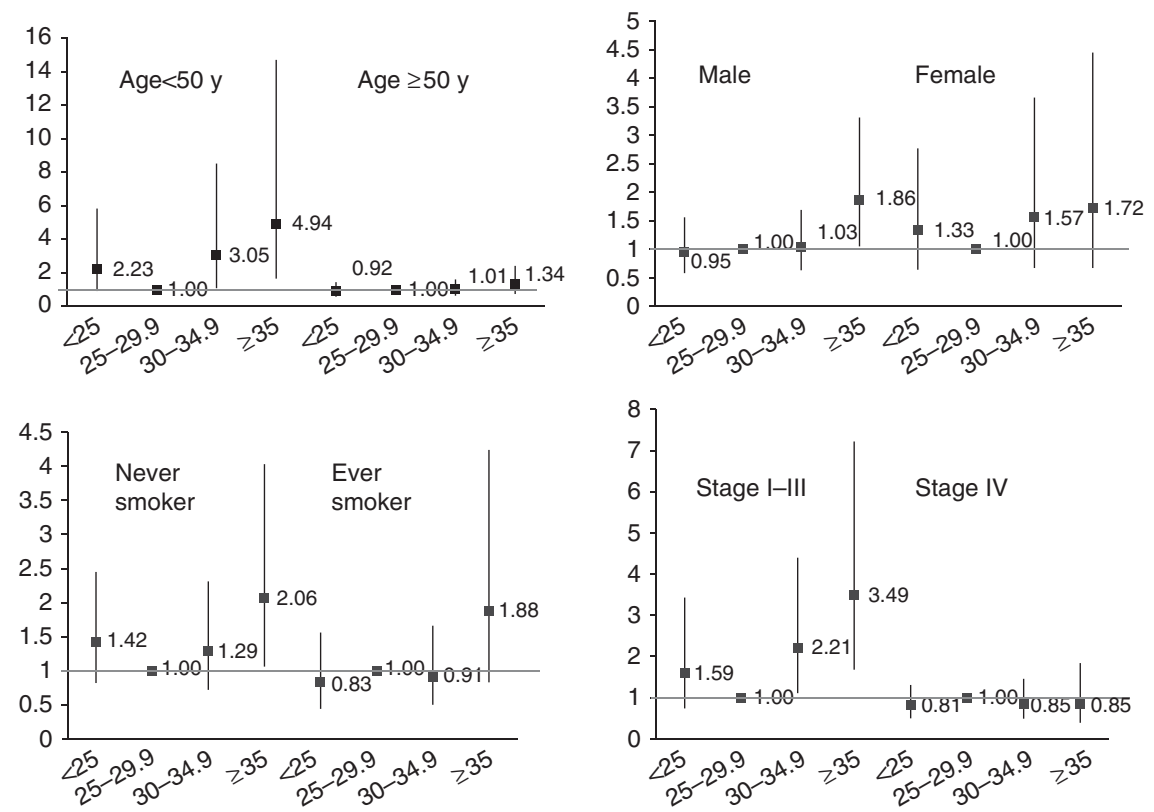

Figure 2. Association between BMI and 10-year overall survival by strata: multivariable-adjusted hazard ratios and $95 \%$ confidence intervals. Model adjusted for age, sex, alcohol drinking status, weight change, clinical stage, grade, and treatment modality.

inflammatory pathways in the tumour microenvironment and in the systemic circulation that stimulate tumour growth, progression, and metastasis (Bardou et al, 2013; Shah et al, 2015). However, only two (Dignam et al, 2006; Sinicrope et al, 2010) of nine previous studies reported significant direct associations between peridiagnostic BMI and CRC survival (Meyerhardt et al, 2003, 2004, 2008; Hines et al, 2009; Baade et al, 2011; Campbell et al, 2012; Kuiper et al, 2012; Yamamoto et al, 2012; Schlesinger et al, 2014). In contrast, nearly all prospective cohort studies with data on prediagnostic BMI reported higher mortality rates among obese, as compared with normal-weight, CRC patients (Doria-Rose et al, 2006; Haydon et al, 2006; Prizment et al, 2010; Campbell et al, 2012; Kuiper et al, 2012; Fedirko et al, 2014; Campbell et al, 2015). The most recent report from the Colon-Cancer Family Registry also found that prediagnostic obese BMI increased mortality in CRC patients irrespective of tumour molecular subtype (Campbell et al, 2015). Much of the variability in the results between pre- and post-diagnostic BMI is attributed to potential reverse causality because of unintentional, cancer-associated weight loss in the period prior to and around diagnosis that is more common among patients with advanced disease.

Differences in CRC patient survival by tumour characteristics, treatment modality, and peridiagnostic weight change, which have not been comprehensively captured in previous prospective cohorts assessing prediagnostic BMI with survival outcomes, appeared to affect our findings. Moderate and severe obesity was most strongly associated with a higher risk of death among stage I-III patients. However, we have previously shown a potential joint prognostic effect of inflammation and obesity in metastatic CRC patients (Shah et al, 2015). Inclusion of older patients and patients reporting weight loss appeared to attenuate or mask associations observed between obesity and OS in all CRC patients; however, none of these factors appeared to strongly impact PFS. One potential explanation is that advanced-stage patients, and similarly older patients or patients experiencing weight loss, represent a group more susceptible to the physiologic stress of cancer as well as aggressive treatment modalities, whereas, obese patients who survive the cancer experience are simply more likely to develop and die from other obesity-related causes (Renehan, 2014). In a recent pooled prospective analysis of BMI and subsequent cancer risk in CRC survivors, individuals who were overweight or obese were at moderate increased risk of developing subsequent obesity-associated cancers. However, the risk observed for second cancers was similar to that of the first primary malignancy and suggested that the elevated risk in CRC survivors may be related to the higher prevalence of overweight and obesity in this group, rather than increased susceptibility (Gibson et al, 2014). Without more specific information on cause of death and few compelling findings for PFS in our analysis, we are not able to further postulate from what or why severely obese cancer patients were more likely to die. However, our findings for the detrimental effects of more extreme levels of obesity among CRC patients are consistent with the results of two large pooled analyses. In over 25000 patients enrolled in adjuvant chemotherapy trials, only severe obesity, as compared with normal weight, was associated with worse disease-free survival (Sinicrope et al, 2013). Similarly, across 20 prospective population-based cohorts, class III obesity (BMI $\geqslant 40 \mathrm{~kg} \mathrm{~m}^{-2}$ ) among cancer-free individuals at baseline was associated with a significantly increased risk of death from malignant neoplasms (Kitahara et al, 2014).

The combination of electronic medical record and patient questionnaire data collected within a single large cancer centre allowed us to begin to address previous limitations from both clinical and population-based cohorts lacking sufficient data on one or more key risk or prognostic factors, such as prediagnostic BMI, drinking and smoking habits, weight change, tumour characteristics, or treatment. Although we had a limited number of underweight patients to evaluate relationships in this group, we had a sufficient number of patients with $\mathrm{BMI} \geqslant 35 \mathrm{~kg} \mathrm{~m}^{-2}$ at diagnosis, allowing us to explore additional and more extreme levels of obesity that are increasingly emerging among cancer patient populations. However, some of our findings among smaller subgroups of patients should be viewed with caution, as it is possible that because of the number of analytic comparisons, some of the more modestly significant results may be attributable to chance. It is also worth noting that although we had patient reports on peridiagnostic weight loss and clinicopathologic data, we did not have information on measured $v s$ self-reported BMI prior to cancer diagnosis or on the specific cause of death. Although the possibility of misclassification of BMI category and residual confounding by unmeasured or shifting factors remains, our strata-specific findings suggest that this would been most likely to have further attenuated the associations we observed for class II obesity. 
Class I and class II obesity was associated with significantly worse survival among patients with localised and locally advanced disease, as well as among younger patients. In conjunction with previous literature, these findings continue to suggest that the link between adiposity and CRC patient survival is complex and that clinicopathologic factors may explain some but not all of this relationship. Given the ever increasing proportion of obese and severely obese adults, and of cancer survivors, concentrated research, surveillance, and intervention efforts are needed to understand and improve long-term outcomes in obese patients presenting with CRC.

\section{ACKNOWLEDGEMENTS}

This work was supported by the National Institutes of Health, National Cancer Institute Cancer Center Support Grant CA016672 (to the University of Texas MD Anderson Cancer Center). The current study was also made possible with the resources and support of the TexGen Foundation.

\section{CONFLICT OF INTEREST}

The authors declare no conflict of interest.

\section{REFERENCES}

American Cancer Society (2014) Colorectal Cancer Facts \& Figures 2014-16. American Cancer Society: Atlanta.

American Cancer Society (2015) Cancer Facts \& Figures 2015. American Cancer Society: Atlanta.

Azvolinsky A (2014) Cancer prognosis: role of BMI and fat tissue. J Natl Cancer Inst 106(6): dju177.

Baade PD, Meng X, Youl PH, Aitken JF, Dunn J, Chambers SK (2011) The impact of body mass index and physical activity on mortality among patients with colorectal cancer in Queensland, Australia. Cancer Epidemiol Biomark Prev 20(7): 1410-1420.

Bardou M, Barkun AN, Martel M (2013) Obesity and colorectal cancer. Gut 62(6): 933-947.

Boyle T, Fritschi L, Platell C, Heyworth J (2013) Lifestyle factors associated with survival after colorectal cancer diagnosis. Br J Cancer 109(3): 814-822.

Campbell PT, Newton CC, Dehal AN, Jacobs EJ, Patel AV, Gapstur SM (2012) Impact of body mass index on survival after colorectal cancer diagnosis: the Cancer Prevention Study-II Nutrition Cohort. J Clin Oncol 30(1): $42-52$.

Campbell PT, Newton CC, Newcomb PA, Phipps AI, Ahnen DJ, Baron JA, Buchanan DD, Casey G, Cleary SP, Cotterchio M, Farris AB, Figueiredo JC, Gallinger S, Green RC, Haile RW, Hopper JL, Jenkins MA, Le Marchand L, Makar KW, McLaughlin JR, Potter JD, Renehan AG, Sinicrope FA, Thibodeau SN, Ulrich CM, Win AK, Lindor NM, Limburg PJ (2015) Association between body mass index and mortality for colorectal cancer survivors: overall and by tumor molecular phenotype. Cancer Epidemiol Biomark Prev 24(8): 1229-1238.

Demark-Wahnefried W, Platz EA, Ligibel JA, Blair CK, Courneya KS, Meyerhardt JA, Ganz PA, Rock CL, Schmitz KH, Wadden T, Philip EJ, Wolfe B, Gapstur SM, Ballard-Barbash R, McTiernan A, Minasian L, Nebeling L, Goodwin PJ (2012) The role of obesity in cancer survival and recurrence. Cancer Epidemiol Biomark Prev 21(8): 1244-1259.

Dignam JJ, Polite BN, Yothers G, Raich P, Colangelo L, O'Connell MJ, Wolmark N (2006) Body mass index and outcomes in patients who receive adjuvant chemotherapy for colon cancer. J Natl Cancer Inst 98(22): 1647-1654.

Doria-Rose VP, Newcomb PA, Morimoto LM, Hampton JM, Trentham-Dietz A (2006) Body mass index and the risk of death following the diagnosis of colorectal cancer in postmenopausal women (United States). Cancer Causes Control 17(1): 63-70.

Doyle C, Kushi LH, Byers T, Courneya KS, Demark-Wahnefried W, Grant B, McTiernan A, Rock CL, Thompson C, Gansler T, Andrews KS; 2006 Nutrition, Physical Activity and Cancer Survivorship Advisory
Committee; American Cancer Society (2006) Nutrition and physical activity during and after cancer treatment: an American Cancer Society guide for informed choices. CA Cancer J Clin 56(6): 323-353.

Eng C, Lynch P, Skibber J (2013) Colon Cancer. In: 60 Years of Survival Outcomes at The University of Texas MD Anderson Cancer Center, Rodriguez MA, Walters RS, Burke TW (eds). Springer: New York, NY, USA, pp 77-84.

Fedirko V, Romieu I, Aleksandrova K, Pischon T, Trichopoulos D, Peeters PH, Romaguera-Bosch D, Bueno-de-Mesquita HB, Dahm CC, Overvad K, Chirlaque MD, Johansen C, Bidstrup PE, Dalton SO, Gunter MJ, Wark PA, Norat T, Halkjaer J, Tjonneland A, Dik VK, Siersema PD, Boutron-Ruault MC, Dossus L, Bastide N, Kuhn T, Kaaks R, Boeing H, Trichopoulou A, Klinaki E, Katsoulis M, Pala V, Panico S, Tumino R, Palli D, Vineis P, Weiderpass E, Skeie G, Gonzalez CA, Sanchez MJ, Barricarte A, Amiano P, Quiros JR, Manjer J, Jirstrom K, Ljuslinder I, Palmqvist R, Khaw KT, Wareham N, Bradbury KE, Stepien M, Duarte-Salles T, Riboli E, Jenab M (2014) Pre-diagnostic anthropometry and survival after colorectal cancer diagnosis in Western European populations. Int J Cancer 135(8): 1949-1960.

Flegal KM, Carroll MD, Kit BK, Ogden CL (2012) Prevalence of obesity and trends in the distribution of body mass index among US adults, 1999-2010. JAMA 307(5): 491-497.

Fleming JB, Gonzalez RJ, Petzel MQ, Lin E, Morris JS, Gomez H, Lee JE, Crane CH, Pisters PW, Evans DB (2009) Influence of obesity on cancerrelated outcomes after pancreatectomy to treat pancreatic adenocarcinoma. Arch Surg 144(3): 216-221.

Gibson TM, Park Y, Robien K, Shiels MS, Black A, Sampson JN, Purdue MP, Beane Freeman LE, Andreotti G, Weinstein SJ, Albanes D, Fraumeni Jr JF, Curtis RE, Berrington de Gonzalez A, Morton LM (2014) Body mass index and risk of second obesity-associated cancers after colorectal cancer: a pooled analysis of prospective cohort studies. J Clin Oncol 32(35): 4004-4011.

Haydon AM, Macinnis RJ, English DR, Giles GG (2006) Effect of physical activity and body size on survival after diagnosis with colorectal cancer. Gut 55(1): 62-67.

Hines RB, Shanmugam C, Waterbor JW, McGwin Jr G, Funkhouser E, Coffey CS, Posey J, Manne U (2009) Effect of comorbidity and body mass index on the survival of African-American and Caucasian patients with colon cancer. Cancer 115(24): 5798-5806.

Kitahara CM, Flint AJ, Berrington de Gonzalez A, Bernstein L, Brotzman M, MacInnis RJ, Moore SC, Robien K, Rosenberg PS, Singh PN, Weiderpass E, Adami HO, Anton-Culver H, Ballard-Barbash R, Buring JE, Freedman DM, Fraser GE, Beane Freeman LE, Gapstur SM, Gaziano JM, Giles GG, Hakansson N, Hoppin JA, Hu FB, Koenig K, Linet MS, Park Y, Patel AV, Purdue MP, Schairer C, Sesso HD, Visvanathan K, White E, Wolk A, Zeleniuch-Jacquotte A, Hartge P (2014) Association between class III obesity (BMI of $40-59 \mathrm{~kg} / \mathrm{m} 2$ ) and mortality: a pooled analysis of 20 prospective studies. PLoS Med 11(7): e1001673.

Kuiper JG, Phipps AI, Neuhouser ML, Chlebowski RT, Thomson CA, Irwin ML, Lane DS, Wactawski-Wende J, Hou L, Jackson RD, Kampman E, Newcomb PA (2012) Recreational physical activity, body mass index, and survival in women with colorectal cancer. Cancer Causes Control 23(12): 1939-1948.

Meyerhardt JA, Catalano PJ, Haller DG, Mayer RJ, Benson 3rd AB, Macdonald JS, Fuchs CS (2003) Influence of body mass index on outcomes and treatment-related toxicity in patients with colon carcinoma. Cancer 98(3): 484-495.

Meyerhardt JA, Niedzwiecki D, Hollis D, Saltz LB, Mayer RJ, Nelson H, Whittom R, Hantel A, Thomas J, Fuchs CS. Cancer and Leukemia Group B 89803 (2008) Impact of body mass index and weight change after treatment on cancer recurrence and survival in patients with stage III colon cancer: findings from Cancer and Leukemia Group B 89803. J Clin Oncol 26(25): 4109-4115.

Meyerhardt JA, Tepper JE, Niedzwiecki D, Hollis DR, McCollum AD, Brady D, O'Connell MJ, Mayer RJ, Cummings B, Willett C, Macdonald JS, Benson 3rd AB, Fuchs CS (2004) Impact of body mass index on outcomes and treatment-related toxicity in patients with stage II and III rectal cancer: findings from Intergroup Trial 0114. J Clin Oncol 22(4): 648-657.

Min YW, Kim SA, Lee JH, Kim JY, Chang DK, Rhee PL, Kim JJ, Rhee JC, Kim YH (2012) Overweight is associated with a favorable survival in patients with colorectal cancer: a prospective cohort study in an Asian population. Ann Surg Oncol 19(11): 3460-3464. 
Murphy TK, Calle EE, Rodriguez C, Kahn HS, Thun MJ (2000) Body mass index and colon cancer mortality in a large prospective study. Am J Epidemiol 152(9): 847-854.

Ogden CL, Carroll MD, Kit BK, Flegal KM (2014) Prevalence of childhood and adult obesity in the united states, 2011-2012. JAMA 311(8): 806-814.

Pajares B, Pollan M, Martin M, Mackey JR, Lluch A, Gavila J, Vogel C, Ruiz-Borrego M, Calvo L, Pienkowski T, Rodriguez-Lescure A, Segui MA, Tredan O, Anton A, Ramos M, Camara MD, Rodriguez-Martin C, Carrasco E, Alba E (2013) Obesity and survival in operable breast cancer patients treated with adjuvant anthracyclines and taxanes according to pathological subtypes: a pooled analysis. Breast Cancer Res 15(6): R105.

Parekh N, Chandran U, Bandera EV (2012) Obesity in cancer survival. Annu Rev Nutr 32: 311-342.

Parkin E, O'Reilly DA, Sherlock DJ, Manoharan P, Renehan AG (2014) Excess adiposity and survival in patients with colorectal cancer: a systematic review. Obes Rev 15(5): 434-451.

Prizment AE, Flood A, Anderson KE, Folsom AR (2010) Survival of women with colon cancer in relation to precancer anthropometric characteristics: the Iowa Women's Health Study. Cancer Epidemiol Biomark Prev 19(9): 2229-2237.

Renehan AG (2014) The 'obesity paradox' and survival after colorectal cancer: true or false? Cancer Causes Control 25(10): 1419-1422.

Schlesinger S, Siegert S, Koch M, Walter J, Heits N, Hinz S, Jacobs G, Hampe J, Schafmayer C, Nothlings U (2014) Postdiagnosis body mass index and risk of mortality in colorectal cancer survivors: a prospective study and metaanalysis. Cancer Causes Control 25(10): 1407-1418.

Shah MS, Fogelman DR, Raghav KP, Heymach JV, Tran HT, Jiang ZQ, Kopetz S, Daniel CR (2015) Joint prognostic effect of obesity and chronic systemic inflammation in patients with metastatic colorectal cancer. Cancer 121(17): 2968-2975.

Simkens LH, Koopman M, Mol L, Veldhuis GJ, Ten Bokkel Huinink D, Muller EW, Derleyn VA, Teerenstra S, Punt CJ (2011) Influence of body mass index on outcome in advanced colorectal cancer patients receiving chemotherapy with or without targeted therapy. Eur J Cancer 47(17): 2560-2567.

Sinicrope FA, Foster NR, Sargent DJ, O'Connell MJ, Rankin C (2010) Obesity is an independent prognostic variable in colon cancer survivors. Clin Cancer Res 16(6): 1884-1893.

Sinicrope FA, Foster NR, Yothers G, Benson A, Seitz JF, Labianca R, Goldberg RM, Degramont A, O'Connell MJ, Sargent DJ. Adjuvant Colon Cancer Endpoints (ACCENT) Group (2013) Body mass index at diagnosis and survival among colon cancer patients enrolled in clinical trials of adjuvant chemotherapy. Cancer 119(8): 1528-1536.

Sturm R, Hattori A (2013) Morbid obesity rates continue to rise rapidly in the United States. Int J Obes (Lond) 37(6): 889-891.

Word Health Organization (2000) Obesity: Preventing and Managing the Global Epidemic. World Health Organization: Geneva.

Wu S, Liu J, Wang X, Li M, Gan Y, Tang Y (2014) Association of obesity and overweight with overall survival in colorectal cancer patients: a metaanalysis of 29 studies. Cancer Causes Control 25(11): 1489-1502.

Yamamoto N, Fujii S, Sato T, Oshima T, Rino Y, Kunisaki C, Masuda M, Imada T (2012) Impact of body mass index and visceral adiposity on outcomes in colorectal cancer. Asia Pacific J Clin Oncol 8(4): 337-345.

Ye Y, Madison B, Wu X, Rustgi AK (2012) A LIN28B polymorphism predicts for colon cancer survival. Cancer Biol Ther 13(14): 1390-1395.

Yuan C, Bao Y, Wu C, Kraft P, Ogino S, Ng K, Qian ZR, Rubinson DA, Stampfer MJ, Giovannucci EL, Wolpin BM (2013) Prediagnostic body mass index and pancreatic cancer survival. J Clin Oncol 31(33): 4229-4234.

This work is published under the standard license to publish agreement. After 12 months the work will become freely available and the license terms will switch to a Creative Commons AttributionNonCommercial-Share Alike 4.0 Unported License.

Supplementary Information accompanies this paper on British Journal of Cancer website (http://www.nature.com/bjc) 